\title{
Article
}

\section{Studies on Indigenous Ion Exchange Resins I: Alkali Metal Ion- Hydrogen Ion Exchange Equilibria}

\author{
Swaminathan Shankar ${ }^{1}$ and Balakrishnan Venkataramani ${ }^{2 *}$ \\ ${ }^{1}$ Hot Cell Development \& Engineering Section, ${ }^{2}$ Analytical Chemistry Division, \\ Bhabha Atomic Research Centre, Trombay, Mumbai 40085, India
}

(Manuscript submitted April 7, 2007; accepted June 5, 2007)

\begin{abstract}
Ion exchange characteristics of gel-type, macroporous and nuclear grade strongly acidic cation exchange resins from three Indian manufacturers were evaluated for their efficacy to remove $\mathrm{Cs}$ and $\mathrm{Sr}$ ions from aqueous solution, which has relevance to the treatment of Low level Liquid Waste (LLW) streams. The alkali metal ion- hydrogen ion exchange equilibria were studied by batch technique at a total ionic strength of $0.1 \mathrm{~mol} \mathrm{dm}^{-3}$. The rational equilibrium constants were determined after incorporating activity coefficient corrections. The selectivity showed the sequence: $\mathrm{Cs}^{+}>\mathrm{K}^{+}>\mathrm{Na}^{+}>\mathrm{Li}^{+}$with respect to $\mathrm{H}^{+}$, indicating that unhydrated ions were preferred. The $\log K_{c}$ vs $\bar{N}_{M}$ (equivalent fraction in the resin phase) plots indicated the heterogeneity in the resin phase and formation of clusters. The gel type resins showed better selectivity for Cs ion.
\end{abstract}

Key words: Indian resins, gel-type, macroporous, nuclear grade, alkali metal ions, equilibrium studies, low level liquid waste

\section{Introduction}

Based on the activity, (liquid) radwaste streams are commonly classified as high level waste (HLW), low level waste (LLW) and intermediate level waste (ILW) [1]. Classification of wastes into different categories is useful in their segregation, selection of appropriate treatment process, storage and disposal. Being versatile, clean, and dynamic in operation, ion exchange is the most preferred technique for the removal of radioactive nuclides (such as Cs, Sr etc.) present in the LLW effluents $[2,3,4]$. These resins after their useful life are immobilized in polymer matrix and stored. All the radioactivity are contained compactly in the ion exchanger column $[3,4]$.

From the point of view of economy and ease of procurement, use of indigenous (organic) ion exchange resin is the obvious option. Two important radio isotopes of concern in LLW stream are ${ }^{137} \mathrm{Cs}$ and ${ }^{90} \mathrm{Sr}$. In order to evaluate the selectivity of the indigenous resin towards these isotopes in proper perspective, alkali metal ion- and alkaline earth metal ion- hydrogen ion exchange equilibria have to be studied both under batch and column conditions. In the present work, gel- and macroporous- type and nuclear grade strongly acidic cation exchange resins (designated as $\mathrm{G}, \mathrm{MP}$ and $\mathrm{N}$ resins having the functional group $-\mathrm{SO}_{3}{ }^{-}$) obtained from three Indian manufacturers (designated 1, 2 and 3 and the resins as G1, G2, G3; MP1, MP2, MP3 and N1, N2, N3) have been used to study the ion exchange characteristics. The performance of the indigenous resins has been compared with data obtained (in this study) using imported resins, gel-type (Dowex 50Wx4 and Dowex 50Wx8) and macroporous resin (Amberlyst-15). The results of the investigations on ion exchange equilibria involving alkali metal ions are presented and discussed in this paper.

\subsection{Preparation of Ion Exchange Resins}

\section{Experimental}

The $\mathrm{H}^{+}$form of the resin was treated with 1 or $0.5 \mathrm{~mol} \mathrm{dm}$ of $\mathrm{MCl}$ solution $\left(\mathrm{M}=\mathrm{Li}^{+}, \mathrm{Na}^{+}, \mathrm{K}^{+}, \mathrm{Cs}^{+}\right)$to convert it to the required alkali metal ionic form. It was later washed free of the salt and stored as air-dried sample. The capacities of the exchanger were determined by standard procedure [5]. The water content of the air dried resin and maximum water uptake of fully swollen resin in different ionic forms were determined by drying them at $100^{\circ} \mathrm{C}$ to constant weight. Capacities on dry basis and equivalent water content of the different ionic forms of the resins are given in Table 1. 


\subsection{Ion Exchange Equilibria}

Known weights (about $0.5 \mathrm{~g}$ ) of the resins in $\mathrm{H}^{+}$-form were equilibrated with $50 \mathrm{~cm}^{3}$ of $0.1 \mathrm{~mol} \mathrm{dm}^{-3}$ $(\mathrm{HCl}+\mathrm{MCl})\left[\right.$ where $\mathrm{M}=\mathrm{Li}^{+}, \mathrm{Na}^{+}, \mathrm{K}^{+}$,] solution for five hours. In the case of $\mathrm{Cs}^{+}-\mathrm{H}^{+}$exchange, $0.05 \mathrm{~mol} \mathrm{dm}^{-3}$ $(\mathrm{HCl}+\mathrm{MCl})$ solution was used. The volumes of $\mathrm{HCl}$ and $\mathrm{MCl}$ in the mixture were varied to give different equivalent fraction $\left(\overline{N_{M}}\right)$ in the exchanger. The $\mathrm{H}^{+}$ion concentration in the equilibrated solution was determined titrimetrically using standard $\mathrm{NaOH}$.

The equilibrium composition of the exchanger and the solution phases were obtained from the amount of exchanger used, its capacity, the concentration of $\mathrm{H}^{+}$at equilibrium and the initial composition of the solution.

\subsection{Treatment of the experimental data}

For the ion exchange equilibria involving uni-univalent cation,

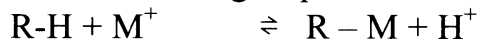

where $\mathrm{R}$ - is the exchanger phase, the equilibrium constant in terms of activity, is given by

$$
K=\frac{\bar{a}_{M} \cdot a_{H}}{\bar{a}_{H} \cdot a_{M}}=\frac{\bar{M} \cdot H}{\bar{H} \cdot M} \times \frac{\gamma_{H}}{\gamma_{M}} \times \frac{f_{M}}{f_{H}}=K_{c} \frac{\gamma^{2}{ }_{ \pm H C l}}{\gamma^{2}{ }_{ \pm M C l}} \times \frac{f_{M}}{f_{H}}=K_{c}^{\prime} \times \frac{f_{M}}{f_{H}}
$$

where $\bar{a}$ refers to the activity in the exchanger phase. The value of $K$ in Eq. (2) depends on the choice of the standard state. In the 'rational approach' [5], the exchanger is considered as a solid solution of two forms of the swollen resin and the standard states are chosen as monoionic $\mathrm{H}^{+}$and $\mathrm{M}^{+}$-forms of the resin. $\gamma_{M}$ and $\gamma_{H}$ are the solution phase activity coefficients of the two ions and $f_{\mathrm{M}}$ and $f_{\mathrm{H}}$ are the resin phase activity coefficients. $K_{c}$ is the stoichiometric concentration product which can be estimated using the equilibrium compositions in solution.

$\bar{N}$ 's and $N$ 's are the equivalent fractions of the ions in the resin and solution phases respectively, $\gamma_{ \pm}$'s are the mean molal activity coefficients for the salts $\mathrm{MCl}$ and $\mathrm{HCl}$ in the aqueous electrolyte mixture. For uni-univalent systems it has been shown that the rational thermodynamic equilibrium constant becomes, [5]

$$
\log K=\int_{0}^{1} \log K_{c} d \overline{N_{M}}+2 \log \frac{\gamma_{ \pm H C l}}{\gamma_{ \pm M C l}}
$$

The area under the curve of the plot of $\log K_{c}$ vs $\bar{N}_{M}$ will give the first term in Eq. (3) to which the solution phase activity coefficient corrections can be added to give the value for the ion exchange equilibrium constant $K$. The mean activity coefficient of the electrolyte in solution phase can be obtained from the literature [6]. Typical ion exchange isotherms for the alkali metal ion $-\mathrm{H}^{+}$for the different resins (plots of equivalent fraction of the metal ion in the exchanger, $\bar{N}_{M}$, against those in the solution, $N_{M}$ ) are shown in Fig. 1. Typical plots of $\log K_{c}$ vs $\bar{N}_{M}$ ) are shown in Fig. 2. The equilibrium constant values obtained from these plots are given in Table 1 .

\section{Results and Discussions}

The ion exchange resins from the Indian manufacturers have been prepared by polymerising styrene with divinyl benzene as cross linking agent. The polymer is later sulphonated. The extent of cross-linking varies from different manufacturer; it will be in the range of 6 to $8 \%$. The nuclear grade resins have higher attrition resistance than gel-type resins. Macroporous resins are prepared using an inert compound during polymerization which is removed later. These resins are mainly used in demineralization plants to prepare hi purity water.

As 12 types of resins have been used in the present study, only typical curves representing their performance are included in the paper.

Among the resins, the ones from manufacturer 3 (namely, G3, MP3 and N3) had low capacities and overall poor selectivity. The resins from the other manufacturers exhibited better performance, based on the shape of the isotherms (Table 1 and Fig. 1).

The variation of $K_{c}$ (or $\log K_{c}$ ) with composition in the resin phase (or loading, $\bar{N}_{M}$ ) reflects heterogeneity in the resins [5]. This has been theoretically demonstrated in the case of an anion exchange system [7]. The variation of $K_{c}$ with $\bar{N}_{M}$ show the deviation from the assumption of treating the ion exchanger as a homogeneous phase, as two resin forms present solid solution. The variations are treated as formation of ion pairs in the resin phase which exist as "clusters", resulting in a heterogeneous phase, as shown in Fig. 2. [5, 8].

Among the resins the ones from manufacturer 3, showed much larger variation of $\log K_{c}$ with $\bar{N}_{M}$ (Fig. 2), than the other resins, indicating the prevalence of clusters of ion pairs in the resin phase. Of the different approaches proposed to explain the ion exchange selectivities, the one put forward by Eisenman [9] and extended by Reichenberg to the organic exchangers [10] is noteworthy. This approach regards the exchange process as a 
Table: 1 Capacities and water contents $\left(n_{w}\right.$ at $\left.a_{w}=1\right)$ for $\mathrm{H}^{+}$and alkali metal ionic forms of indigenous ion exchange resins and equilibrium constant $(\mathrm{K})$ for alkali metal ions $-\mathrm{H}^{+}$exchange

\begin{tabular}{|c|c|c|c|c|c|c|c|c|c|}
\hline Resin & Ion & $\begin{array}{c}\text { Cap. } \\
\text { (meq/g) }\end{array}$ & $n_{w}$ & $\mathrm{~K}^{*}$ & Resin & Ion & $\begin{array}{c}\text { Cap. } \\
\text { (meq/g) }\end{array}$ & $n_{w}$ & $\mathrm{~K}^{*}$ \\
\hline \multirow[t]{5}{*}{ G 1} & $\mathrm{H}^{+}$ & 4.86 & 10.8 & - & N 1 & $\mathrm{H}^{+}$ & 4.73 & 10.4 & - \\
\hline & $\mathrm{Li}^{+}$ & 4.44 & 9.6 & 1.10 & & $\mathrm{Li}^{+}$ & 4.30 & 12.3 & 0.81 \\
\hline & $\mathrm{Na}^{+}$ & 4.16 & 9.1 & 1.64 & & $\mathrm{Na}^{+}$ & 4.27 & 11.7 & 1.13 \\
\hline & $\mathrm{K}^{+}$ & 3.99 & 7.4 & 1.74 & & $\mathrm{~K}^{+}$ & 3.96 & 10.1 & 1.16 \\
\hline & $\mathrm{Cs}^{+}$ & 2.73 & 7.1 & 3.30 & & $\mathrm{Cs}^{+}$ & 2.98 & 9.8 & 2.84 \\
\hline \multirow[t]{5}{*}{ G 2} & $\mathrm{H}^{+}$ & 5.20 & 13.4 & - & N 2 & $\mathrm{H}^{+}$ & 5.17 & 10.4 & - \\
\hline & $\mathrm{Li}^{+}$ & 4.67 & 11.2 & 0.93 & & $\mathrm{Li}^{+}$ & 4.56 & 11.3 & 0.92 \\
\hline & $\mathrm{Na}^{+}$ & 4.34 & 10.9 & 1.24 & & $\mathrm{Na}^{+}$ & 4.59 & 10.2 & 1.62 \\
\hline & $\mathrm{K}^{+}$ & 4.17 & 9.3 & 1.79 & & $\mathrm{~K}^{+}$ & 4.22 & 9.0 & 2.25 \\
\hline & $\mathrm{Cs}^{+}$ & 2.90 & 9.0 & 3.38 & & $\mathrm{Cs}^{+}$ & 3.05 & 8.7 & 2.83 \\
\hline \multirow[t]{5}{*}{ G 3} & $\mathrm{H}^{+}$ & 3.67 & 14.8 & - & N 3 & $\mathrm{H}^{+}$ & 3.47 & 14.3 & - \\
\hline & $\mathrm{Li}^{+}$ & 3.21 & 16.9 & 0.64 & & $\mathrm{Li}^{+}$ & 3.02 & 17.0 & 0.46 \\
\hline & $\mathrm{Na}^{+}$ & 3.28 & 16.0 & 1.25 & & $\mathrm{Na}^{+}$ & 2.93 & 16.0 & 0.66 \\
\hline & $\mathrm{K}^{+}$ & 2.93 & 14.6 & 1.21 & & $\mathrm{~K}^{+}$ & 2.80 & 15.7 & 1.07 \\
\hline & $\mathrm{Cs}^{+}$ & 2.22 & 11.6 & 2.73 & & $\mathrm{Cs}^{+}$ & 2.19 & 14.5 & 1.55 \\
\hline \multirow[t]{5}{*}{ MP 1} & $\mathrm{H}^{+}$ & 4.26 & 15.9 & - & $\begin{array}{l}\text { Dowex } \\
50 \mathrm{Wx} 4\end{array}$ & $\mathrm{H}^{+}$ & 5.16 & 23.2 & - \\
\hline & $\mathrm{Li}^{+}$ & 4.03 & 13.9 & 1.84 & & $\mathrm{Li}^{+}$ & 5.01 & 20.5 & 3.28 \\
\hline & $\mathrm{Na}^{+}$ & 3.78 & 13.6 & 1.69 & & $\mathrm{Na}^{+}$ & 4.63 & 19.8 & 1.85 \\
\hline & $\mathrm{K}^{+}$ & 3.53 & 12.2 & 1.95 & & $\mathrm{~K}^{+}$ & 4.13 & 19.4 & 3.32 \\
\hline & $\mathrm{Cs}^{+}$ & 2.65 & 11.8 & 2.72 & & $\mathrm{Cs}^{+}$ & 2.91 & 14.8 & 1.60 \\
\hline \multirow[t]{5}{*}{ MP 2} & $\mathrm{H}^{+}$ & 4.78 & 15.7 & - & $\begin{array}{l}\text { Dowex } \\
50 \mathrm{Wx} 8\end{array}$ & $\mathrm{H}^{+}$ & 5.26 & 10.4 & - \\
\hline & $\mathrm{Li}^{+}$ & 4.43 & 15.5 & 1.02 & & $\mathrm{Li}^{+}$ & 5.09 & 10.4 & 0.65 \\
\hline & $\mathrm{Na}^{+}$ & 4.32 & 14.3 & 1.31 & & $\mathrm{Na}^{+}$ & 4.50 & 10.1 & 1.42 \\
\hline & $\mathrm{K}^{+}$ & 3.70 & 14.5 & 2.88 & & $\mathrm{~K}^{+}$ & 4.20 & 8.9 & 1.77 \\
\hline & $\mathrm{Cs}^{+}$ & 2.77 & 13.9 & 4.84 & & $\mathrm{Cs}^{+}$ & 3.03 & 8.7 & 3.37 \\
\hline \multirow[t]{5}{*}{ MP 3} & $\mathrm{H}^{+}$ & 2.65 & 16.9 & - & $\begin{array}{c}\text { Amberl- } \\
\text { yst-15 }\end{array}$ & $\mathrm{H}^{+}$ & 4.83 & 11.8 & - \\
\hline & $\mathrm{Li}^{+}$ & 1.88 & 25.4 & 0.41 & & $\mathrm{Li}^{+}$ & 4.57 & 11.2 & 0.65 \\
\hline & $\mathrm{Na}^{+}$ & 1.91 & 21.4 & 0.26 & & $\mathrm{Na}^{+}$ & 4.35 & 10.7 & 1.73 \\
\hline & $\mathrm{K}^{+}$ & 1.75 & 21.2 & 1.07 & & $\mathrm{~K}^{+}$ & 3.91 & 9.4 & 3.68 \\
\hline & $\mathrm{Cs}^{+}$ & 1.39 & 19.9 & 1.65 & & $\mathrm{Cs}^{+}$ & 2.75 & 9.2 & 3.97 \\
\hline
\end{tabular}
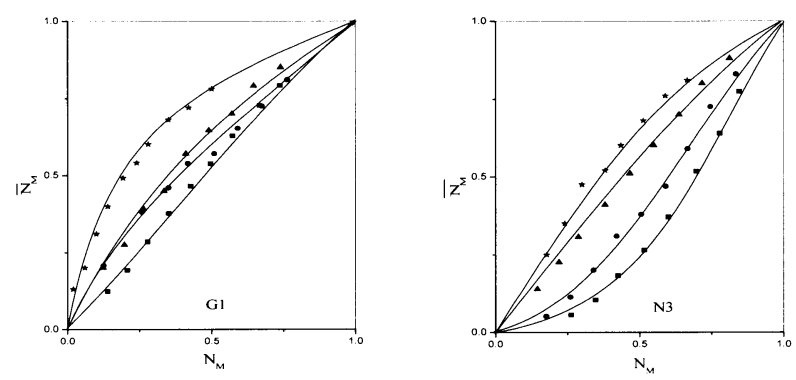

Fig. 1 Alkali metal ion $-\mathrm{H}^{+}$exchange isotherms

( $\bar{N}_{M}$ vs $N_{M}$ ) on indigenous resins

(- $\mathrm{Li}^{+}-\mathrm{H}^{+}$exchange; $(\bullet) \mathrm{Na}^{+}-\mathrm{H}^{+}$exchange;

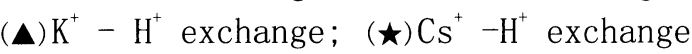
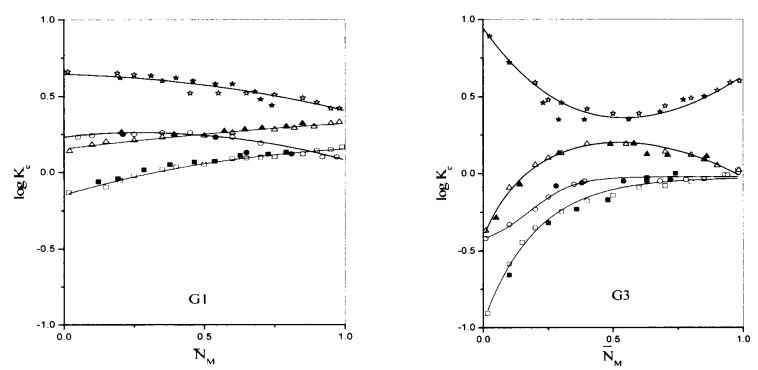

Fig.2 Variation of selectivity Coefficient $\left(K_{c}\right)$ with loading $\bar{N}_{M}$ for alkali metal ion $-\mathrm{H}^{+}$exchanges on indigenous resins

$(\boldsymbol{\bullet}, \square) \mathrm{Li}^{+}-\mathrm{H}^{+}$exchange; $(\bullet, 0) \mathrm{Na}^{+}-\mathrm{H}^{+}$exchange;

$(\boldsymbol{\Lambda}, \triangle) \mathrm{K}^{+}-\mathrm{H}^{+}$exchange; $(\boldsymbol{\star}, \boldsymbol{\star}) \mathrm{Cs}^{+}-\mathrm{H}^{+}$exchange 
competition between the hydration tendency of the counter ion in solution and the electrostatic interaction with the ionogenic group in the exchanger phase. Ion exchangers whose ionogenic group has weak field strength (for example, $-\mathrm{SO}_{3}{ }^{-}$group) prefer ion that are less hydrated, exhibiting a selectivity sequence: $\mathrm{Cs}^{+}>\mathrm{Rb}^{+}>\mathrm{K}^{+}>\mathrm{Na}^{+}>$ $\mathrm{Li}^{+}$. The selectivity sequence exhibited by the resins under present study (Table 1) indicates that the ionogenic group present in them have weak field strength typical of strongly acidic cation exchanger having $-\mathrm{SO}_{3}^{-}$as functional group.

The parameter, $a^{0}$, the distance of closest approach, used in Debye-Hueckel theory of electrolyte solution, could be taken as an index of ionic hydration [11]. Typical linear relation between $\log K($ from Table 1$)$ and $1 / a^{0}$ shown in Fig. 3, indicates that hydrated alkali metal ions are involved in the exchange process.

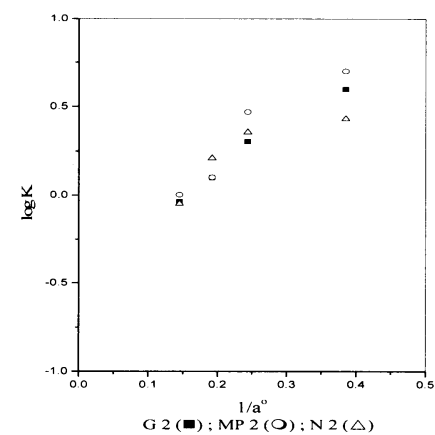

Fig. 3 Relation between selectivity coefficient $(K)$ with Debye Hueckel parameter $\left(a^{0}\right)$ for alkali metal ion- $\mathrm{H}^{+}$ exchanges on indigenous resins

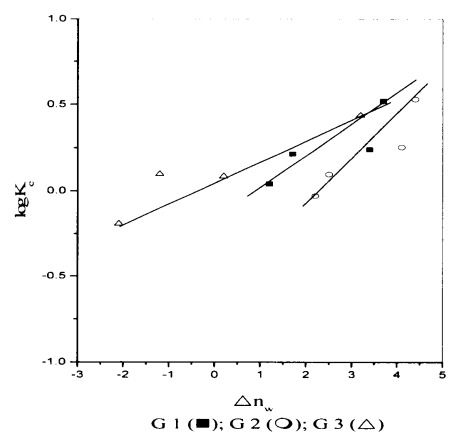

Fig. 4 Variation of equilibrium constant $(\log K)$ as a function of changes in the water content, $\triangle n_{w}$ $\left[\triangle n_{w}=n_{w}\left(\mathrm{H}^{+}\right)-\right.$ $\left.n_{w}\left(\mathrm{M}^{+}\right)\right]$for alkali metal ion $-\mathrm{H}^{+}$ion exchanges on indigenous resins

A net gain in entropy, as compared to the enthalpy change, is the driving force for the overall exchange process [12]. This has been established for many ion exchange systems [12,13]. The gain in entropy is associated with the net release of water per equivalent of exchanging ion during the process $[14,15]$.

Typical plots of $\log K$ vs $\Delta n_{w}$ [where $\left.\Delta n_{w}=n_{w}\left(\mathrm{H}^{+}\right)-n_{w}\left(\mathrm{M}^{+}\right)\right]$at $a_{w}=1$ (in Table 1) for the various ion exchange systems in the present study are shown in Fig. 4. A general linear relation between $\log K$ and $\Delta n_{w}$ could be deduced, indicating the validity of the approach.

Indian gel-type resins are better than the macroporous and nuclear grade resins. Based on the analysis of the data on capacity, water content and the selectivity obtained in this study, the overall performance of the resin from the Indian manufacturers could be formulated as: (manufacturer 1) slightly better than (manufacturer 2) better than (manufacturer 3). From the point of view of selectivity for $\mathrm{Cs}^{+}$, the performance of G1 and G2 are comparable to Dowex $50 \mathrm{~W} \times 8$.

\section{References}

1. Radioactive waste management (Eds. J.H. Saling and A.W. Fewiman), ${ }^{\text {nd }}$ Edn., Taylor and Francis, New York, 2002.

2. Operation and control of ion exchange processes for treatment of radioactive wastes, Tech. Report Ser.78, IAEA, Vienna (1967).

3. Treatment of spent ion exchange resins for storage and disposal, Tech. Report Ser. 254, IAEA,Vienna (1985)

4. Application of ion exchange processes for the treatment of radioactive wastes and management of ion exchangers, Tech. Report Ser. 408, IAEA, Vienna (2002).

5. F. Helfferich, Ion exchange, McGraw Hill and Co., New York, 1962.

6. R.A. Robinson and R.H. Stokes, Electrolytic solutions, Butterworth, London, 1969.

7. D.H. Freeman, J. Chem. Phys., 35, 189-191 (1961).

8. H.P. Gregor, J. Belle and R.A. Marcus, J. Am. Chem. Soc., 77, 2713-2719 (1955).

9. G. Eisenman, in 'Membrane transport and metabolism', (Eds. A. Kleinzeller and A. Kotyk), Academic Press, New York, 1961, 163-179; Biophys. J., Suppl., 2(2), 259-323 (1962).

10. D. Reichenberg, in Ion exchange, (Ed. J.A. Marinsky), Marcel Dekker Inc., New York, 1966, Vol. 1, $227-276$

11. G.E. Boyd, J. Schubert and A.W. Adamson, J. Am. Chem. Soc., 69, 2818 -2829 (1947).

12. R.S.D. Toteja, B.L. Jangida, M. Sundaresan and B. Venkataramani, Langmuir, 13, 2980-2982 (1997) .

13. G.E. Boyd, F. Vaslow and S., Lindenbaum, J. Phys. Chem., 68, 590-597 (1964); 71, 2214-2219 (1967).

14. H.L. Yeager, ACS Symp. Ser., 180, 25-39 (1982).

15. Sita T. Iyer, D. Nandan and B. Venkataramani, React. Funct. Polym., 29, 51-57 (1996). 